\title{
PENGARUH TEKANAN DAN WAKTU DEPOSISI SPUTTERING TERHADAP SENSITIVITAS SENSOR GAS $\mathrm{SnO}_{2}$
}

\author{
Sayono, Agus Santoso \\ Puslitbang Teknologi Maju-BATAN \\ Jl. Babarsari Kotak Pos 1008, Yogyakarta 55010
}

\begin{abstract}
ABSTRAK
PENGARUH TEKANAN DAN WAKTU DEPOSISI SPUTTERING TERHADAP SENSITIVITAS SENSOR GAS SnO $\mathrm{S}_{2}$. Telah dilakukan penelitian mengenai pengaruh variasi tekanan dan waktu deposisi sputtering terhadap sensitivitas sensor gas $\mathrm{SnO}_{2}$ yang difabrikasi dengan metode DC sputtering. Variasi tekanan dimulai dari $3 \times 10^{-2}, 4 \times 10^{-2}, 5 \times 10^{-2}, 6 \times 10^{-2}$ dan $7 \times 10^{-2}$ Torr serta variasi waktu dimulai dari 30, 60, 90 dan 120 menit dengan tegangan tinggi DC sebesar $2 \mathrm{kV}$ dan suhu deposisi $250{ }^{\circ} \mathrm{C}$. Hasil eksperimen menunjukkan bahwa lapisan tipis $\mathrm{SnO}_{2}$ yang dideposisi dengan parameter sputtering : tegangan $2 \mathrm{kV}$, arus $10 \mathrm{~mA}$, tekanan $7 \times 10^{-2}$ Torr, waktu 120 menit dan suhu $250{ }^{\circ} \mathrm{C}$ mempunyai sensitivitas optimun untuk mendeteksi gas $\mathrm{C}_{2} \mathrm{H}_{5} \mathrm{OH}, \mathrm{NH}_{3}$, CO dan $\mathrm{HNO}_{3}$. Dari hasil pengujian sensitivitas menunjukkan bahwa sensor gas dari bahan $\mathrm{SnO}_{2}$ mempunyai sensitivitas tertinggi terhadap gas $\mathrm{C}_{2} \mathrm{H}_{5} \mathrm{OH}$ dengan sensitivitas $46,96 \%$ dan gas $\mathrm{NH}_{3}$ dengan sensitivitas $41,91 \%$ pada konsentrasi 5.529 ppm. Kemudian dari hasil analisa unsur dan tebal lapisan $\mathrm{SnO}_{2}$ pada kondisi optimum menggunakan SEM-EDS diperoleh Sn sebesar 30,68\% dan O sebesar 69,32 \% dan tebal lapisan $\mathrm{SnO}_{2}$ sebesar $\pm 4,5 \mu \mathrm{m}$.
\end{abstract}

Kata kunci : Sputtering, Deposisi, Suhu sensor dan Sensitivitas.

\begin{abstract}
THE INFLUENCE OF THE PRESSURE AND TIME DEPOSITION TO SENSITIVITY OF THE SnO THIN FILMS GAS SENSOR. Research on the influence of pressure and time deposition on the sensitivity of gas sensor fabricated using technique DC Sputtering has been done. The variation of pressure were 3 $\times 10^{-2}, 4 \times 10^{-2}, 5 \times 10^{-2}, 6 \times 10^{-2}$ and $7 \times 10^{-2}$ Torr and time variation were $30,60,90$, and 120 minutes, $D C$ high voltage was $2 \mathrm{kV}$ and temperature deposition was $250{ }^{\circ} \mathrm{C}$. The results showed that $\mathrm{SnO}_{2}$ thin films with parameter proces voltage $2 \mathrm{kV}$, current $10 \mathrm{~mA}$, pressure $7 \times 10^{-2}$ Torr, time 120 minutes and temperature deposition was $250{ }^{\circ} \mathrm{C}$ have optimum sensitivity to detect : $\mathrm{C}_{2} \mathrm{H}_{5} \mathrm{OH}, \mathrm{NH}_{3}$, $\mathrm{CO}$ dan $\mathrm{HNO}_{3}$ gas. Results showed that the optimum sensitivity for gas $\mathrm{C}_{2} \mathrm{H}_{5} \mathrm{OH}$ was 46,95 \% and $\mathrm{NH}_{3} 41,91 \%$. Measured at 5,529 ppm. SEM-EDS analysis showed that at this condition the thickness of $\mathrm{SnO}_{2}$ thin film was inorder of $\pm 4,5 \mu \mathrm{m}$, while the content of oxygen (O) and Sn were $69,32 \%$ and 30,60\% respectively.
\end{abstract}

Key word : Sputtering, Deposition, Sensor temperature and Sesitivity

\section{PENDAHULUAN}

$\mathrm{P}$ enelitian dan pengembangan bahan sensor gas khususnya untuk pendeteksian gas-gas berbahaya telah dilakukan manusia sejak 40 tahun terakhir. Saat itu, Seiyama dan Taguchi pertama kali menerapkan prinsip interaksi atom dan molekul dengan permukaan bahan semikonduktor untuk pendeteksian gas berbasis sensor gas chemoresistive (perubahan tahanan/resistansi bahan akibat serapan kimia gas) ${ }^{(1)}$.
Semikonduktor oksida mempunyai rancangan sederhana dan harga yang relatif murah, hal ini menyebabkan mereka menonjol sebagai pilihan untuk digunakan dalam penyediaan perangkat multi-sensor ${ }^{(2)}$. Walaupun demikian penggunaan semikonduktor oksida sebagai sensor gas terus mengalami penyempurnaan khususnya sifat sensitivitas dan selektivitas yang merupakan dua isu penting dalam perangkat sensor gas.

Lapisan tipis oksida logam merupakan satu jenis dari sekian banyak bahan lapisan 
tipis yang telah dikembangkan menjadi sensor gas semikonduktor. Keadaan ini dimung- kinkan karena struktur dan sifat elektrik lapisan tipis oksida dapat dikontrol dalam proses pembuatannya, sehingga dapat merubah tingkat sensitivitasnya jika berada dalam lingkugan gas.

Banyak teknik yang digunakan untuk membuat lapisan tipis (thin film), diantaranya adalah dengan metode sputtering. Metode sputtering mempunyai keunggulan diantaranya : dapat menyediakan bahan lapisan tipis yang seragam, padat (dense), memenuhi stoikiometri dan apabila proses sputtering telah dimatikan, maka seluruh proses deposisi akan segera berhenti ${ }^{(3)}$.

Pada proses sputtering, besaran yang cukup penting adalah sputtering yield yang didefinisikan sebagai jumlah atom yang dipancarkan dari target per ion datang. Sputtering yield dipengaruhi oleh beberapa faktor diantaranya massa ion target, massa ion penembak, energi ion datang dan suhu target, sedangkan sifat dan struktur hasil dari lapisan tipis dengan teknik dc sputtering dipengaruhi oleh parameter proses diantaranya : tekanan gas, waktu sputtering, tegangan, arus dan suhu subsrat.

Pada penelitian ini telah dilakukan variasi parameter proses sputtering yakni tekanan dan waktu untuk memperoleh parameter proses yang tepat/kondisi optimun sehingga diperoleh lapisan tipis $\mathrm{SnO}_{2}$ yang dapat digunakan sebagai bahan sensor gas dengan mempunyai sensitivitas tinggi.

Untuk mengetahui keberhasilan dari pembuatan lapisan tipis $\mathrm{SnO}_{2}$ dengan DC sputtering, maka dilakukan karakterisasi yang meliputi : pengukuran resistansi dan sensitivitas/kepekaan tangap terhadap gas : $\mathrm{C}_{2} \mathrm{H}_{5} \mathrm{OH}, \mathrm{CO}, \mathrm{HNO}_{3}$ dan $\mathrm{NH}_{3}$, analisa struktur kristal, ketebalan lapisan dan komposisi kimia.

Untuk menganalisa struktur kristal digunakan alat XRD (X-Ray Diffraction) sedang untuk analisa struktur mikro, pengukuran tebal lapisan $\mathrm{SnO}_{2}$ dan unsur dari lapisan $\mathrm{SnO}_{2}$ digunakan SEM-EDS (Scanning Electron Microscopy-Energy Dispersive X-Ray Spectroscopy).

Penelitian ini dilakukan dengan maksud dan tujuan untuk memperoleh pengetahuan dan penguasaan teknologi pembuatan lapisan tipis $\mathrm{SnO}_{2}$ sebagai bahan sensor gas dengan metode $D C$ sputtering. Sedang manfaatnya adalah ini dapat diperoleh suatu bahan baru yang dapat digunakan untuk pembuatan sensor gas yang mempunyai sensitivitas tinggi.

\section{DASAR TEORI}

Sistem DC sputtering terdiri dari dua elektroda yaitu anoda dan katoda. Pada anoda ditempatkan substrat (bahan yang akan dilapisi) yang dilengkapi dengan pemanas untuk membuka pori-pori substrat, sehingga bahan yang dideposisi di atas permukaan substrat dapat melekat lebih kuat dan tidak mudah mengelupas. Pada katoda dipasang bahan target dan dilengkapi dengan pendingin (water cooling system) yang berfungsi menghindarkan bahan target agar tidak meleleh akibat suhu yang terlalu tinggi.

Untuk membersihkan molekul-molekul dalam tabung reaktor plasma sehingga diperoleh tekanan yang rendah, maka dilakukan penghampaan dengan pompa rotari dan difusi hingga tekanan $10^{-5}$ Torr.

\section{Parameter Proses Sputtering}

Waktu dan tekanan merupakan parameter yang memegang peran penting dalam proses sputtering. Semakin lama waktu yang diperlukan untuk proses sputtering, maka akan semakin besar pula jumlah bahan yang terpercik.

Banyaknya bahan yang terpercik per satuan luas katoda secara matematis dapat diformulasikan sebagai berikut ${ }^{(4)}$ :

$$
W_{0}=\frac{j_{+} S t A}{e N_{A}}
$$

dengan: $j_{+}=$rapat arus berkas ion $\left(\mathrm{mA} / \mathrm{cm}^{2}\right)$, $S=$ sputter yield (atom/ion), $t=$ waktu sputtering (detik), $A$ = berat atom (amu), $e=$ 
muatan elektron $\left(1,6 \times 10^{23}\right.$ atom/mol $)$ dan $N_{A}=$ bilangan Avogadro.

Jumlah bahan yang terpercik menempel pada substrat secara matematis diformulasikan sebagai berikut ${ }^{(4)}$ :

$$
W \cong k \frac{W_{0}}{p d}
$$

dengan $k=$ konstanta $=r_{c} r_{a}$ dengan $r_{c}$ dan $r_{a}$ masing-masing adalah jari-jari katoda dan anoda (bernilai 1 untuk system planar), $W_{0}=$ banyak partikel yang terpercik dari satuan luas katode, $p=$ tekanan gas lucutan (Torr) dan $d=$ jarak antara elektroda (m)

Laju pemindahan atom permukaan yang diakibatkan oleh penembakan ion disebut sebagai hasil sputter (S), yang secara matematis diformulasikan sebagai ${ }^{(4)}$ :

$$
S=\frac{\text { Atom yang dipindahkan }}{\text { Ion yang datang }}
$$

\section{Energi Sputtering}

Pendeposisian lapisan tipis pada substrat merupakan bentuk transfer energi atau transfer momentum. Energi kinetik ion-ion positif yang tertarik ke bahan target (katoda) berasal dari medan listrik akibat beda potensial yang diberikan. Agar proses deposisi dapat terjadi, maka besar energi kinetik ion-ion positif harus lebih besar daripada energi ikat bahan target. Besarnya energi yang dipindahkan saat proses tumbukan dapat yang secara matematis dirumuskan $^{(4)}$ :

$$
E_{1}=\frac{4 M_{1} M_{2}}{\left(M_{1}+M_{2}\right)^{2}} E_{2}
$$

dengan $E_{1=}$ energi kinetik partikel penumbuk, $M_{1=}$ massa partikel penumbuk, $M_{2}=$ massa partikel target, $E_{2}=$ energi yang ditransfer partikel bermassa $M_{1}$ ke atom $M_{2}$.

Adanya tumbukan dari ion-ion positif sebesar $E_{1}$ menyebabkan atom-atom bahan target tercungkil dan akibat adanya transfer momentum atom tersebut terpercik ke segala arah utamanya ke arah substrat. Karena proses tersebut berlangsung kontinyu selama waktu tertentu, proses pelapisan akan berlangsung terus sehingga terjadi interdifusi antar atom hingga terbentuk suatu lapisan tipis.

\section{Mekanisme Serapan Gas}

Bahan semikonduktor sensor gas tersusun atas sensor kimia listrik yang mampu merespon perubahan lingkungan kimia dengan menghasilkan sinyal listrik. Cara kerja sensor gas semikonduktor berpedoman pada fakta bahwa karakteristik listrik dari bahan bergantung pada jumlah molekul teradsorbsi ${ }^{(5) .}$

Terdapat dua jenis serapan yang terjadi pada semikonduktor oksida logam, yaitu serapan fisika dan serapan kimia. Serapan fisika pada proses adsorbsi adalah serapan gas akibat adanya gaya Van der Walls. Sedangkan serapan kimia pada adsorbsi terkait dengan pembentukan ikatan kimia antara molekul teradsorbsi dengan permukaan semi- konduktor oksida logam ${ }^{(6)}$.

\section{Serapan Gas}

Pada kondisi udara normal, permukaan bahan semikonduktor terlapisi oleh suatu lapisan yang diakibatkan oleh terserapnya oksigen. Proses ini meliputi penyerapan fisika, yang kemudian diikuti penyerapan kimia dengan menangkap elektron dari daerah dekat permukaan semikonduktor. Proses terserap- nya gas oksigen di atas permukaan semi- konduktor yang secara matematis dapat di tulis ${ }^{(7)}$ :

$$
\begin{aligned}
\frac{1}{2} O_{2}(g) & \longleftrightarrow O \text { (ads) } \\
O \text { (ads) }+2 \mathrm{e} & \longleftrightarrow O^{2-} \text { (ads) }
\end{aligned}
$$

Pernyataan tersebut telah dibuktikan dengan analisa menggunakan $x$-ray photoelektron spectroscopy (XPS), yang menunjukkan adanya kehadiran serapan oksigen secara kimia. Sebagai hasil dari serapan kimia oksigen, terbentuk depletion layer dan potensial schottky Barrier permukaan, dimana kosentrasi elektron adalah rendah dibandingkan dengan yang terdapat dalam bulk. Menurut teori cacat, 
terikatnya atom oksigen di atas permukaan semikonduktor menyebabkan hadirnya cacat titik yaitu interstisial ion oksigen pada kisi kristal. Reaksi absorsi penangkapan elektron gas oksigen di atas permukaan substrat menimbulkan perubahan sifat elektrik bahan sensor yang signifikan pada kondisi normal. Jika suhu dinaikkan hingga mencapai keadaan kesetimbangan termodinamik maka atom oksigen yang teradsorbsi di atas permukaan dapat menarik elektron dari dalam bulk ${ }^{(8)}$, hal ini menyebabkan panjang depletion layer akan meningkat.

\section{Sensitivitas}

Sensitivitas merupakan kemampuan sensor untuk mendeteksi kehadiran sejumlah gas dalam jumlah yang kecil, yang secara matematis dapat diformulasikan ${ }^{(9)}$ :

$S=\frac{\Delta R}{R_{n}} \times 100 \%=\frac{\left|R_{n}-R_{g}\right|}{R_{n}} \times 100 \%$

dengan $S$ = sensitivitas (\%), $R_{n}=$ resistansi pada udara normal $(\Omega), R_{g}=$ resistansi ketika diberi gas $(\Omega)$, dengan $R_{n}$ dan $R_{g}$ terukur pada kondisi isotermal.

\section{TATA KERJA PENELITIAN}

\section{Pembuatan Target dan Penyiapan substrat}

Pembuatan target $\mathrm{SnO}_{2}$ dilakukan dengan mencampur 40 gram bubuk $\mathrm{SnO}_{2}$ dengan alkohol sehingga diperoleh bubuk adonan yang relatif lembab untuk dapat dibuat dalam bentuk pelet, kemudian adonan tersebut dipres dengan tekanan $200 \mathrm{kN}$ selama kurang lebih 5 - 10 menit sehingga diperoleh pelet $\mathrm{SnO}_{2}$ dengan diameter 60 $\mathrm{mm}$ serta ketebalan $3 \mathrm{~mm}$. Selanjutnya agar diperoleh pelet yang lebih keras dan tidak mudah pecah, maka target tersebut dianil pada suhu $800{ }^{\circ} \mathrm{C}$ selama dua jam.

Substrat yang akan dideposisi terbuat dari kaca preparat dengan tebal $1 \mathrm{~mm}$ dan dipotong dengan ukuran $10 \times 20 \mathrm{~mm}^{2}$. Kemudian untuk membersihkan kotoran/ lemak yang menempel di atas permukaan substrat, maka substrat dicuci detergen dan alkohol menggunakan ultrasonic cleaner masing-masing selama 20 menit. Selanjutnya substrat dikeringkan menggunakan pemanas pada suhu $100{ }^{\circ} \mathrm{C}$ selama1 jam.

\section{Pembuatan lapisan tipis $\mathrm{SnO}_{2}$}

Pada pembuatan lapisan tipis $\mathrm{SnO}_{2}$ di atas permukaan substrat kaca terdiri dari 2 tahap yakni proses pendeposisian lapisan tipis $\mathrm{SnO}_{2}$ dan tahap pembuatan kontak perak pada lapisan tipis. Pendeposisian dilakukan dengan menvariasi parameter proses yaitu waktu, tegangan tinggi dc (HV) dan tekanan sputtering. Skema alat DC Sputtering disajikan pada Gambar 1.

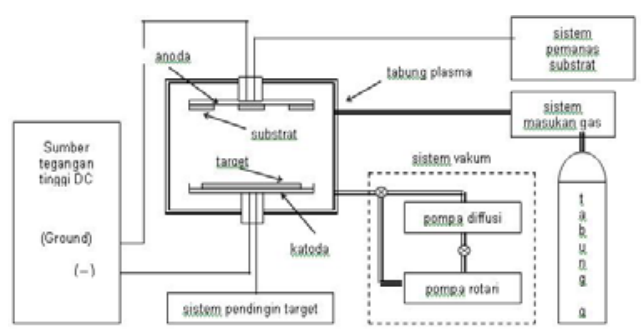

Gambar 1.: Sistem DC sputtering

Proses pendeposisian lapisan tipis $\mathrm{SnO}_{2}$ adalah sebagai berikut: memasang target $\mathrm{SnO}_{2}$ pada katoda dan substrat kaca yang telah dibersihkan pada anoda. Kemudian tabung reaktor plasma dihampakan dengan pompa rotari hingga mencapai tekanan $10^{-2}$ torr, kemudian pompa difusi dihidupkan untuk menghampakan tabung sputtering agar dicapai tingkat kevakuman $10^{-4}$ torr, selanjutnya gas argon dimasukkan ke dalam tabung sputtering hingga tekanan kerja operasi tercapai $\left(10^{-2}\right.$ torr), selanjutnya tegangan tinggi dc dihidupkan hingga mencapai tegangan $2 \mathrm{kV}$. Langkah pendeposisian diulangi untuk setiap pasangan tekanan dan waktu deposisi yaitu pada variasi tekanan : $3 \times 10^{-2}, 4 \times 10^{-2}$, $5 \times 10^{-2} 1, \quad 6 \times 10^{-2}$,dan $\quad 7 \times 10^{-2} \quad$ Torr masing-masing dengan waktu deposisi selama : 30, 60, 90 dan 120 menit. Hal ini dilakukan untuk memperoleh data parameter proses terkanan dan waktu sputtering yang optimum, sehingga dihasilkan lapisan tipis 
$\mathrm{SnO}_{2}$ yang homogen di atas permukaan substrat kaca.

Untuk mengetahui keberhasilan pembuatan lapisan tipis dari parameter proses yaitu tekanan dan waktu deposisi, maka dilakukan pengukuran resistansi untuk menentukan suhu operasi sensor, sensitivitas terhadap gas : $\mathrm{CO}, \mathrm{C}_{2} \mathrm{H}_{5} \mathrm{OH}, \mathrm{HNO}_{3}$ dan $\mathrm{NH}_{3}$. dan juga analisa struktur kristal, struktur mikro, analisa unsur dan pengukuran tebal lapisan tipis $\mathrm{SnO}_{2}$.

\section{HASIL DAN PEMBAHASAN}

Untuk mengetahui pengaruh tekanan dan waktu sputtering $\mathrm{SnO}_{2}$ terhadap resistansi dan sensitvitas sensor gas dengan variasi tekanan : $3 \times 10^{-2}, 4 \times 10^{-2}, 5 \times 10^{-2}$, $6 \times 10^{-2}$,dan $7 \times 10^{-2}$ Torr masing-masing dengan waktu deposisi selama : 30, 60, 90 dan 120 menit, maka dilakukan karakterisasi yang meliputi: pengukuran resistansi, suhu sensor, sensitivitas, analisa struktur kristal, analisa struktur mikro, analisa unsur dan tebal lapisan tipis $\mathrm{SnO}_{2}$

\section{Penentuan Resistansi dan Suhu Sensor}

Pengukuran resistansi $(R)$ untuk menentukan suhu operasi sensor dilakukan dengan cara menvariasi suhu mulai dari suhu kamar $29{ }^{\circ} \mathrm{C}-350{ }^{\circ} \mathrm{C}$ dengan kenaikan suhu tiap $25{ }^{0} \mathrm{C}$. Pemilihan batas maksimal suhu $350 \quad{ }^{0} \mathrm{C}$ dikarenakan $\mathrm{SnO}_{2}$ tergolong semikonduktor oksida logam yang memiliki gejala efek konduktansi permukaan (surface conductance effect) sehingga memiliki unjuk kerja yang sangat baik sebagai sensor gas pada suhu antara (200-400) ${ }^{0} \mathrm{C}$ (Cobos, 2001). Pengukuran resistansi sensor gas $\mathrm{SnO}_{2}$ dengan tekanan dan waktu yang divariasi terhadap suhu seperti yang disajika pada Gambar 2a dan 2b.

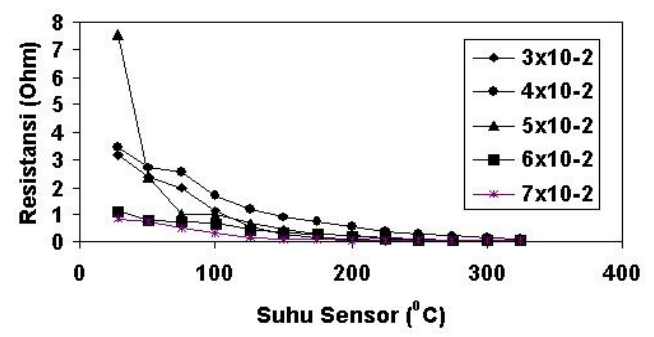

Gambar 2a. : Pengaruh resistansi lapisan tipis $\mathrm{SnO}_{2}$ terhadap suhu untuk berbagai variasi tekanan sputtering

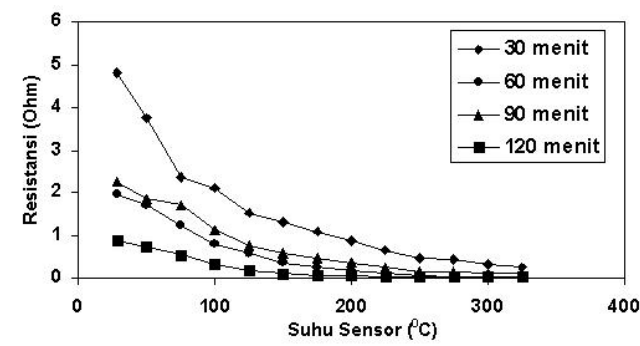

Gambar 2b. : Pengaruh resistansi lapisan tipis $\mathrm{SnO}_{2}$ terhadap suhu untuk berbagai variasi waktu sputtering

Pada Gambar 2a dan 2b. menunjukkan bahwa besarnya resistansi terendah dicapai pada tekanan sputtetring $7 \times 10^{-2}$ torr dengan waktu selama 120 menit. Ini menunjukkan bahwa bahan sensor gas $\mathrm{SnO}_{2}$ yang telah diteliti dengan variasi waktu dan tekanan sputtering menghasilkan nilai resistansi terendah/terbaik dicapai pada tekanan $7 \times 10^{-2}$ torr dengan waktu selama 120 menit. Hal ini terjadi pada tekanan sputtering $7 \times 10^{-2}$ torr, gas argon yang dimasukkan ke dalam tabung sputtering sebagai gas pembawa muatan jumlahnya semakin besar bila dibanding dengan tekanan yang lain, akibatnya jumlah atom-atom $\mathrm{SnO}_{2}$ yang terpercik (sputtering yield) dari target menuju substrat juga semakin banyak. Demikian juga dengan bertambahnya waktu sputtering menjadi 120 menit, maka jumlah atom-atom yang menuju substrat akan bertambah semakin banyak. Akibat dari pengaruh dari kedua parameter tersebut akan menghasilkan atom-atom 
$\mathrm{SnO}_{2}$ yang terkumpul di atas permukaan substrat semakin besar sehingga berpengaruh terhadap naiknya konduktivitas atau menurunnya resistansi bahan sensor.

Penurunan resistansi bahan semikonduktor $\mathrm{SnO}_{2}$ juga dipengaruhi oleh kenaikan suhu. Tetapi walaupun suhu terus dinaikkan penurunan nilai resistansi akan semakin kecil dan menuju kondisi yang stabil. Hal ini sebagai akibat adanya migrasi elektron dari pita valensi menuju ke pita konduksi (menjadi elektron bebas). Pada keadaan suhu $250-325{ }^{\circ} \mathrm{C}$ penurunan nilai resistansi telah menunjukkan kestabilan. Hal ini berarti bahwa nilai resistansi pada kondisi tertentu nilainya sudah tidak terpengaruh oleh kenaikan suhu, pada kondisi rentang suhu tersebut bahan $\mathrm{SnO}_{2}$ dapat berfungsi sebagai sensor gas karena perubahan nilai resistansi tidak dipengaruhi oleh panas tetapi disebabkan adanya proses serapan gas yang mengenai permukaan bahan sensor.

Apabila suhu sensor terus dinaikkan, maka resistansi kembali menunjukkan gejala kenaikan hal ini sesuai pendapat Gaskov dan Rumyantseva (1999) yang mengatakan bahwa hal tersebut dapat terjadi karena pada suhu di atas suhu operasi sensor, oksigen yang teradsorbsi akan menarik elektron dari bagian dalam butir yang mengakibatkan pertambahan ketebalan lapisan deplesi yang terlalu besar sehingga seluruh butir akan berada pada daerah bebas/kosong elektron yang menyebabkan peningkatan resistivitas.

\section{Sensitivitas Sensor Gas $\mathrm{SnO}_{2}$ untuk Berbagai Gas Uji}

Pengujian sensitivitas sensor gas $\mathrm{SnO}_{2}$ menggunakan 4 jenis gas yaitu $\mathrm{C}_{2} \mathrm{H}_{5} \mathrm{OH}$, $\mathrm{NH}_{3}, \mathrm{HNO}_{3}$, dan $\mathrm{CO}$. Keempat gas uji tersebut dipilih berdasar pertimbangan sebagai gas polutan. Grafik hubungan antara sensitivitas terhadap volume gas disajikan pada

Gambar 3.

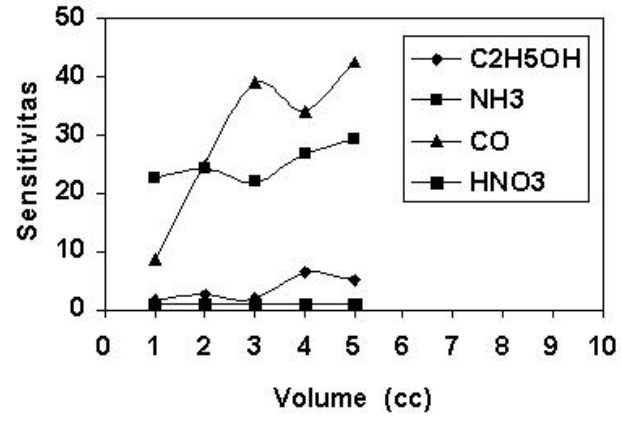

Gambar 3. Hubungan antara sensitivitas terhadap volume gas : $\mathrm{O}_{2}, \mathrm{C}_{2} \mathrm{H}_{5} \mathrm{OH}, \mathrm{NH}_{3}$ dan $\mathrm{HNO}_{3}$

Gambar 3. menunjukkan bahwa sensor gas $\mathrm{SnO}_{2}$ yang telah dibuat mempunyai respon terbaik untuk $\mathrm{C}_{2} \mathrm{H}_{5} \mathrm{OH}$ (alkohol) pada konsentrasi 5.529 ppm (1 cc) dengan sensitivitas tertinggi 46,95 \% dan gas $\mathrm{NH}_{3}$ dengan berkonsentrasi terkecil 5.529 ppm (1 cc) dengan sensitivitas tertinggi 41,91\%. Hal ini karena molekul oksigen (O) pada etanol akan mengikat molekul oksigen (O) pada permukaan sensor gas menjadi $\mathrm{O}_{2}$ dan memberi pengaruh terhadap penurunan resistansi demikian juga untuk gas $\mathrm{NH}_{3}$, karena molekul hidrogen $\left(\mathrm{H}_{2}\right)$ dari $\mathrm{NH}_{3}$ akan mengikat molekul oksigen (O) pada permukaan sensor menjadi $\mathrm{H}_{2} \mathrm{O}$ maka akibatnya akan memberikan efek penurunan resistansi yang menyebabkan kenaikan sensitivitas sensor.

Untuk mendeteksi gas $\mathrm{HNO}_{3}$, sensor gas dari bahan $\mathrm{SnO}_{2}$ mempunyai respon kecil dengan sensitivitas $0,98 \%$, hal ini terjadi karena molekul oksigen $(\mathrm{O})$ pada $\mathrm{HNO}_{3}$ akan terikat pada molekul oksigen (O) di permukaan sensor menjadi $\mathrm{O}_{2}$ yang berpengaruh terhadap kenaikan resistansi. Naiknya resistansi bahan sensor karena gas ini akan mengikat lebih banyak elektron bebas di permukaan sensor mengakibatkan jumlah elektron bebas berkurang dan bertambahnya panjang lapisan deplesi dan penghalang antar butir, sehingga terjadi penurunan sensitivitas. 


\section{Analisis dengan X-Ray Diffraction}

Untuk mengetahui struktur kristal lapisan tipis $\mathrm{SnO}_{2}$ yang dihasilkan dari proses sputttering sebagai bahan sensor gas, maka dilakukan anakisa menggunakan XRD (X-Ray Diffraction). Adapun bahan sensor yang diuji adalah sensor $\mathrm{SnO}_{2}$ dengan sensitivitas paling optimum yang diperoleh dengan waktu sputtering 120 menit pada tekanan operasi masing-masing adalah : $3 \times$ $10^{-2}, 5 \times 10^{-2}$ dan $7 \times 10^{-2}$ Torr.

Telah diketahui bahwa $\mathrm{SnO}_{2}$ berstruktur tetragonal, maka orientasi kristalnya dapat diketahui berdasarkan parameter kisi $a=b \neq c$ dan sudut $2 \theta$ untuk tiap puncak intensitas. Perolehan orientasi kristal didapatkan melalui dua metode, yaitu pencocokan jarak antar atom hasil spektrum energi sinar-x dengan jarak antar atom pada tabel JCPDS, dan perhitungan pencarian konstanta kisi menggunakan metode eliminasi terhadap nilai setiap hkl (diketahui sudut $2 \theta, \lambda$ panjang gelombang $\mathrm{Cu}$ ). Grafik hubungan intensitas terhadap sudut $2 \theta$ disajikan pada Gambar 4:

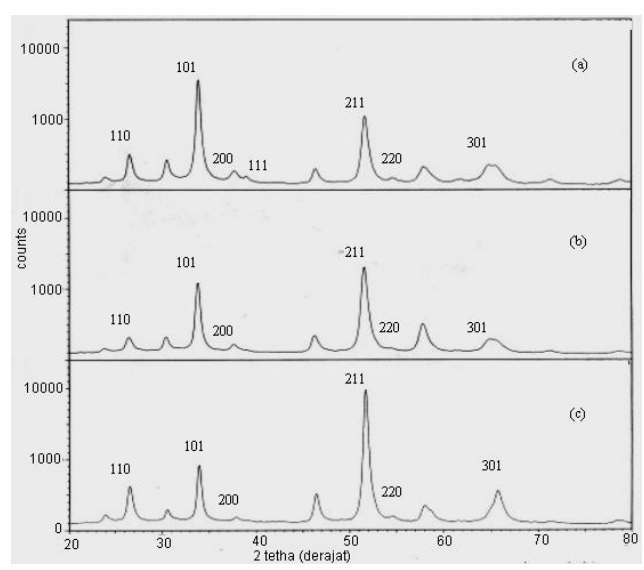

Gambar 4. Hasil defraksi sinar-X dari lapisan tipis $\mathrm{SnO}_{2}$ dengan waktu sputtering 120 menit pada tekanan sputtering (a) $3 \times 10^{-2}$ Torr, (b) $5 \times 10^{-2}$ Torr dan (c) $7 \times 10^{-2}$ Torr

Hasil difraksi sinar-x dari lapisan tipis $\mathrm{SnO}_{2}$ terhadap sudut $2 \theta$ dengan waktu sputtering 120 menit pada tekanan sputtering (a) $3 \times 10^{-2}$ Torr, (b) $5 \times 10^{-2}$ Torr dan (c) $7 \times 10^{-2}$ Torr di sajikan pada Gambar 4 . Adapun ketiga sensor gas dari bahan $\mathrm{SnO}_{2}$ hasil sputtering dengan variasi tekanan operasi adalah sebagai berikut :

Gambar 4a. waktu sputtering 120 menit, tekanan sputtering $3 \times 10^{-2}$ Torr. Didapatkan bidang-bidang $\mathrm{SnO}_{2}$ adalah [110], [101], [200], [111], [211], [220], [301]. Puncak tertinggi pada sudut $2 \theta=33,8997^{\circ}$ pada bidang [101].

Gambar 4b. waktu sputtering 120 menit, tekanan sputtering $5 \times 10^{-2}$ Torr. Didapatkan bidang-bidang $\mathrm{SnO}_{2}$ adalah [110], [101], [200], [211], [220], [301]. Puncak tertinggi pada sudut $2 \theta=51,6064^{\circ}$ pada bidang [211].

Gambar 4c. waktu sputtering 120 menit, tekanan sputtering $7 \times 10^{-2}$ Torr. Didapatkan bidang-bidang $\mathrm{SnO}_{2}$ adalah [110], [101], [200], [211], [220], [301]. Puncak tertinggi pada sudut $2 \theta=51,7173^{\circ}$ pada bidang [211].

Dari ketiga sensor memperlihatkan adanya struktur kristal $\mathrm{SnO}_{2}$ yang berbeda yaitu : Gambar 4a pada tekanan $3 \times 10^{-2}$ Torr bidang 101 mencapai puncak tertinggi pada posisi sudut $2 \theta=33,8997^{\circ}$ dan mengalami penurunan intensitas secara berturut-turut dan penurunan terendah seperti disajikan pada Gambar 4b dan Gambar 4c. Sedangkan untuk bidang [211] mengalami kenaikan intensitas berturut-turut dari seperti disajikan pada Gambar 4a, Gambar 4b dan mencapai puncak tertinggi pada Gambar $5 \mathrm{c}$ pada posisi $2 \theta=51,7173^{\circ}$.

Fenomena penurunan dan kenaikan intensitas pada masing-masing sensor dipengaruhi oleh tekanan deposisi. Karena tekanan deposisi akan menetukan banyaknya atom-atom $\mathrm{SnO}_{2}$ yang terdeposit di atas permukaan substrat, semakin rendah tekanan deposisi maka atom-atom $\mathrm{SnO}_{2}$ yang terdeposit akan semakin banyak, ini sesuai pendapat Wasa, K., Hayakawa, S yang menyatakan bahwa tekanan sputtering berpengaruh terhadap jumlah bahan yang 
terdeposit pada substrat seperti yang disajikan pada persamaan (2). Dengan semakin banyaknya atom-atom yang terdeposit akan berpengaruh terhadap tumbuhnya atom-atom $\mathrm{SnO}_{2}$ di atas permukaan substrat yang semakin rapi/teratur dengan teraturnya atom-atom tersebut maka akan mempertinggi intensitas.

\section{Analisis Unsur dan Struktrur mikro dengan SEM-EDS}

Morfologi permukaan pada lapisan tipis $\mathrm{SnO}_{2}$ hasil DC sputtering ditunjukkan oleh Gambar 5a dan 5b. Dari Gambar 5a menunjukkan bahwa pada deposisi 30 menit, butir-butir $\mathrm{SnO}_{2}$ yang terdeposit terlihat lebih kecil dan rapat dibandingkan pada deposisi 120 menit yang ditunjukkan pada Gambar 5b. Hal ini terjadi karena waktu untuk deposisi masih terlalu rendah sehingga atom-atom yang terdeposit masih sedikit . Tetapi setelah waktu deposisi ditingkatkan menjadi 120 menit, maka selain akan meningkatkan jumlah atom $\mathrm{SnO}_{2}$ di atas permukaan juga dengan bertambahnya waktu deposisi akan menyebabkan terjadinya panas yang timbulkan oleh proses deposisi tersebut. Dengan timbulnya panas akibat proses deposisi akan berpengaruh terhadap ukuran butir atom $\mathrm{SnO}_{2}$ yang
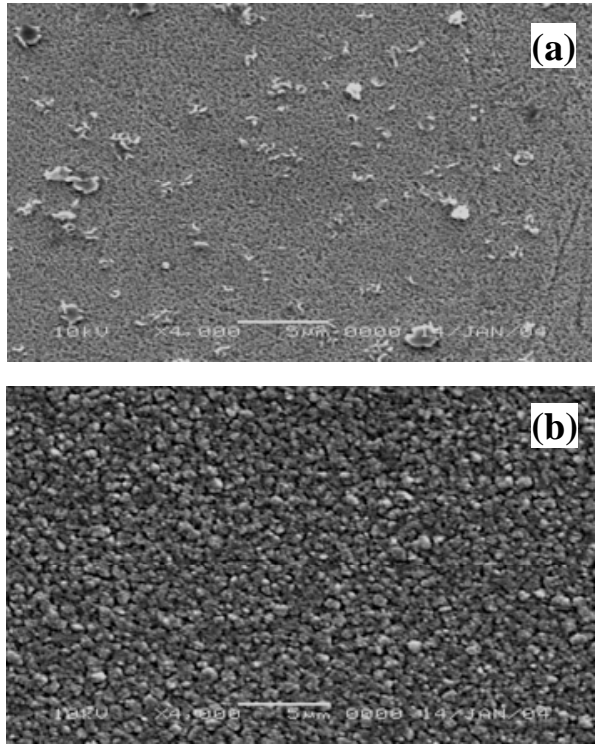

Gambar 5. Morfologi permukaan lapisan tipis $\mathrm{SnO}_{2}$ hasil DC sputtering dengan waktu deposisi 30 menit dan waktu 120 menit pada tekanan sputtering $7 \times 10^{-2}$ Torr dengan pembesaran 4.000 kali

Hasil analisa unsur lapisan tipis $\mathrm{SnO}_{2}$ dari hasil sputtering mengunakan EDS (Electron Dispersive X-Ray Spectroscopy) disajikan pada Gambar 6a. dan 6b. semakin besar.

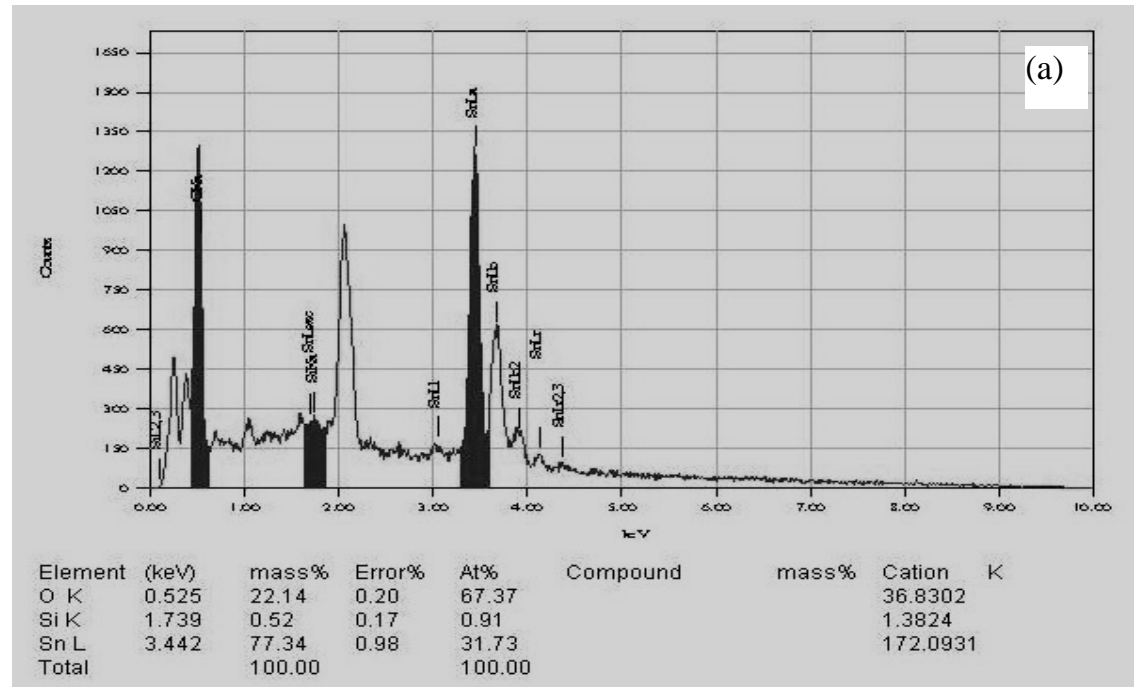


Gambar 6a. Analisis unsur lapisan tipis $\mathrm{SnO}_{2}$ hasil DC sputtering dengan waktu deposisi 30 menit pada tekanan sputtering $3 \times 10^{-2}$ Torr

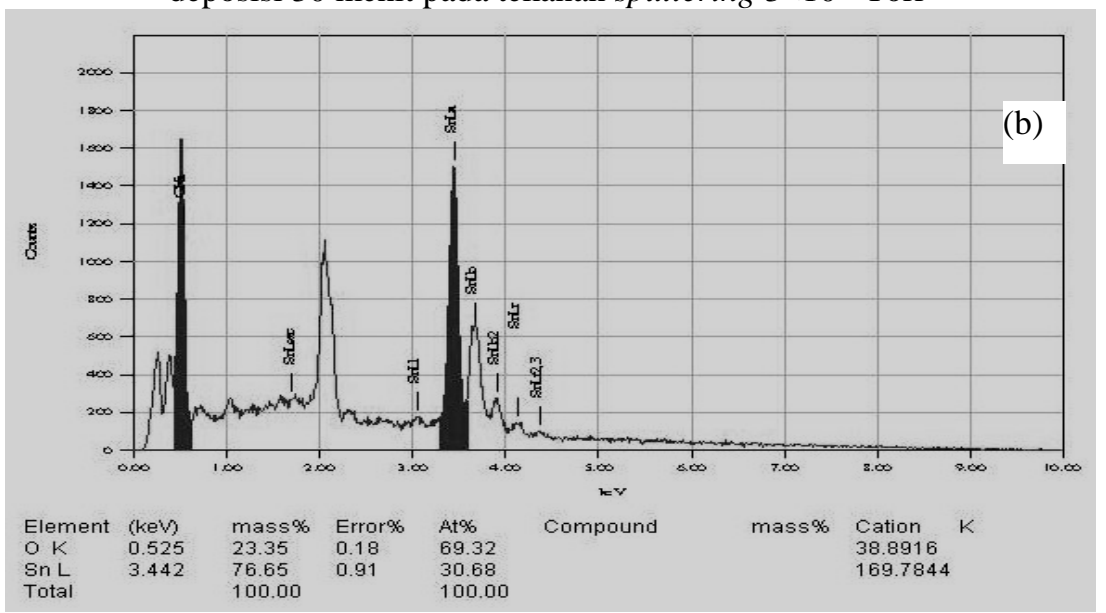

Gambar 6b. Analisis unsur lapisan tipis $\mathrm{SnO}_{2}$ hasil $D C$ sputtering dengan waktu deposisi 120 menit pada tekanan sputtering $7 \times 10^{-7}$ Torr.

Pada Gambar 6a menunjukkan perbandingan \% atom untuk unsur Sn dan O pada lapisan tipis $\mathrm{SnO}_{2}$ hasil sputtering. Dari analisis unsur dengan EDS tersebut menunjukkan bahwa banyaknya atom $\mathrm{O}$ sebesar 67,37 \%, atom Si 0,91 \% dan atom Sn $31,73 \%$ yang berarti setiap atom Sn mengikat 2 atom oksigen, kemudian munculnya atom Si menunjukkan terdeteksinya atom substrat sebagai bahan induk. Hal ini terjadi karena waktu deposisi yang relatif pendek (30) menit membuat atom-atom $\mathrm{SnO}_{2}$ yang terdeposisi belum mampu menutup seluruh permukaan substrat. Sedang pada Gambar 6b. menunjukkan bahwa banyaknya atom O sebesar 69,32 \%, dan atom Sn 30,73. Setelah waktu deposisi dinaikan dai 30 menit menjadi 120 menit, maka atom-atom $\mathrm{SnO}_{2}$ yang terdeposit di atas permukaan substrat semakin banyak hal ini akan berpengaruh pada naiknya prosentase unsur O dan penurunan unsur Sn. Dalam hal ini unsur Si sudah tidak terdeteksi lagi karena seluruh permukaan substrat telah dipenuhi oleh atom $\mathrm{SnO}_{2}$ yang semakin rapat.
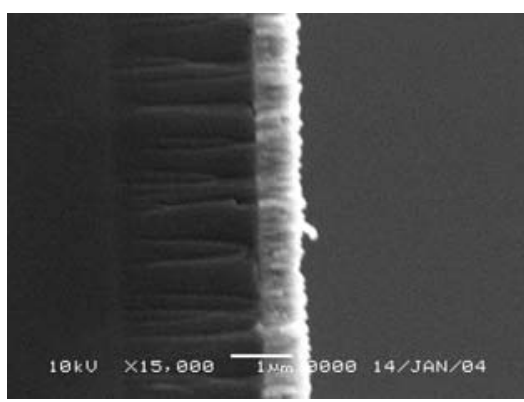

(a) Perbesaran 15000 kali

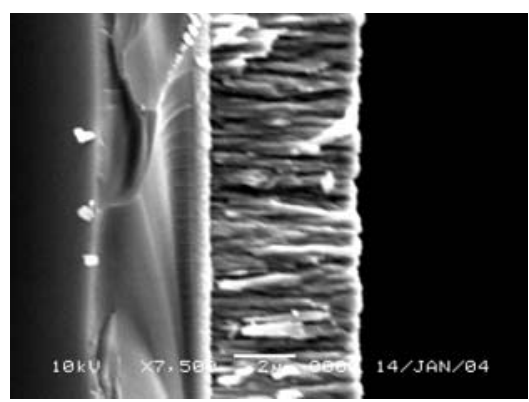

(b) Perbesaran 7500 kali

Gambar 7. Tebal lapisan tipis $\mathrm{SnO}_{2}$ hasil $D C$ sputtering dengan waktu deposisi 30 menit dan waktu deposisi 120 menit pada tekanan sputtering $7 \times$ $10^{-2}$ Torr 
Pada pengukuran tebal lapisan tipis $\mathrm{SnO}_{2}$ pada substrat kaca yang dipotong melintang diperoleh dari hasil SEM tipis seperti terlihat pada Gambar 7a dan 7b berikut ini:

Pada Gambar 7a dan 7b menunjukkan waktu sputtering sangat berpengaruh terhadap tebal lapisan yang terbentuk. Waktu deposisi yang semakin lama akan menambah ketebalan lapisan tipis $\mathrm{SnO}_{2}$. Untuk waktu deposisi 30 menit diperoleh tebal lapisan $\mathrm{SnO}_{2}$ sebesar $\pm 0,8 \mu \mathrm{m}$ dan setelah waktu deposisi dinaikkan sampai 120 menit, maka tebal lapisan menjadi 4,5 $\mu \mathrm{m}$. Hal ini terjadi karena waktu deposisi yang semakin lama, maka atom-atom target yang tersputter/ terpercik menuju substrat akan semakin banyak oleh karena energinya sama (2 kV, arus $10 \mathrm{~mA}$ ) sehingga terjadi pengumpulan atom-atom $\mathrm{SnO}_{2}$ di atas permukaan tertentu yang menyebabkan lapisan $\mathrm{SnO}_{2}$ semakin tebal.

\section{KESIMPULAN}

Penelitian pengaruh tekanan dan waktu sputtering terhadap lapisan tipis $\mathrm{SnO}_{2}$ sebagai bahan dasar sensor gas menghasilkan kesimpulan sebagai berikut :

1. Telah berhasil dibuat lapisan tipis $\mathrm{SnO}_{2}$ hasil DC sputtering sebagai bahan dasar sensor gas dengan suhu operasi sensor gas $\mathrm{SnO}_{2}$ adalah $275^{\circ} \mathrm{C}$.

2. Sensor gas $\mathrm{SnO}_{2}$ yang dibuat dengan waktu sputtering 120 menit dan tekanan sputtering $3 \times 10^{-2}$ Torr mempunyai sensitivitas terbaik untuk gas $\mathrm{C}_{2} \mathrm{H}_{5} \mathrm{OH}$ dengan sensitivitas $46,95 \%$ dan gas $\mathrm{NH}_{3}$ dengan sensitivitas 41,91\% serta kurang respon terhadap gas $\mathrm{HNO}_{3}$ karena hanya mempunyai sensitivitas $0,98 \%$.

3. Tekanan dan waktu deposisi mempunyai pengaruh terhadap tebal lapisan yang terbentuk. Semakin lama waktu deposisi maka lapisan tipis $\mathrm{SnO}_{2}$ yang terbentuk akan semakin tebal. Untuk waktu deposisi selama 30 menit menghasilkan tebal lapisan sebesar $\pm 0,8$ $\mu \mathrm{m}$ dan setelah waktu deposisi ditambah menjadi 120 menit maka menghasilkan tebal lapisan sebesar $\pm 4,5 \mu \mathrm{m}$.

\section{UCAPAN TERIMA KASIH}

Dengan telah selesainya penelitian ini kami mengucapkan banyak terima kasih kepada Bapak :

J. Karmadi, Sumarmo, Sukosrono dan seluruh staf kelompok Pengembangan Aplikasi Akselerator atas segala bantuan yang telah diberikan.

\section{DAFTAR PUSTAKA}

1. TAMAKI, J., XU, C., MIURA, N., YAMAZOE, N., Grain Size Effects on Gas Sensitivity of Porous SnO²-based Elements, Sensors and Actuators B, 3, 147-155, 1991.

2. COSANDEY, F., SKANDON, G., SINGHAL, A, Material and Processing Issues in Nanostructured Semiconductor Gas Sensors, The Minerals, Metals and Materials Society, 2000.

3. MARDARE, D., RUSU, G.L., Structural and Electrical Properties of $\mathrm{TiO} 2 \mathrm{RF}$ Sputerred Thin Films, Materials Science and Engineering, B75, 68-71, 2000.

4. WASA, K., HAYAKAWA, S., Handbook of Sputter Deposition Technology: Principles, Technology and Application, Noyes Publication, New Jersey, 1992.

5. MYASEDOV, B.F., DAVYDOVS, A.V, Chemical Sensors Potentialities and Prospect, Zh. Anal, Khim, Vol. 45, No. 7, 1259-1278.., 1990.

6. OSCIK, J., Adsorbsion, Ellis Horwood Limited Publisher, Chichester, John Willey and Son, New York, USA, 1982.

7. MROWEC, S., Defect and diffusion in solids, Elsevier Scientific Publishing Company, Polandia, 1980

8. GAS`KOV, A.M., RUMYANTSEVA, M.N., Materials for Solid-State Gas Sensors, Inorganic Materials, Vol. 36, No. 3, 293-301, 2000. 
9. XU, C., TAMAKI, J., MIURA, N., YAMAZOE, N., Grain Size Effect on Gas Sensitivity of Porous $\mathrm{SnO}_{2}$ Based Element, Sensor and Actuators B, 147-155, 1991. 